\title{
Author Correction: Temperature Chaos, Memory Effect, and Domain Fluctuations in the Spiral Antiferromagnet Dy
}

\author{
Sergey Kustov ${ }^{1}$, Iuliia Liubimova ${ }^{2}$, Miguel Corró ${ }^{1}$, Joan Torrens-Serra ${ }^{1}$, Xiebin Wang ${ }^{3}$,
} Charles R. S. Haines ${ }^{4}$ \& Ekhard K. H. Salje $\mathbb{C}^{4,5}$

Correction to: Scientific Reports https://doi.org/10.1038/s41598-019-41566-7, published online 25 March 2019

The Acknowledgements section in this Article is incorrect.

"The work was supported by the Spanish Ministerio de Economía y Competitividad, ProjectMAT201456116-C04-01-R and by the Ministry of Education and Science of the Russian Federation, goszadanie No. 3.1421.2017/4.6. EKHS is grateful to EPSRC (EP/P024904/1) and the Leverhulme trust (EM-2016-004)."

Should read:

“The work was supported by FEDER/Ministerio de Ciencia, Innovación y Universidades - Agencia Estatal de Investigación/MAT2014-56116-C04-01-R and by the Ministry of Education and Science of the Russian Federation, goszadanie No. 3.1421.2017/4.6. EKHS is grateful to EPSRC (EP/P024904/1) and the Leverhulme trust (EM-2016-004)."

(i) Open Access This article is licensed under a Creative Commons Attribution 4.0 International License, which permits use, sharing, adaptation, distribution and reproduction in any medium or format, as long as you give appropriate credit to the original author(s) and the source, provide a link to the Creative Commons license, and indicate if changes were made. The images or other third party material in this article are included in the article's Creative Commons license, unless indicated otherwise in a credit line to the material. If material is not included in the article's Creative Commons license and your intended use is not permitted by statutory regulation or exceeds the permitted use, you will need to obtain permission directly from the copyright holder. To view a copy of this license, visit http://creativecommons.org/licenses/by/4.0/.

(C) The Author(s) 2019

\footnotetext{
${ }^{1}$ Department of Physics, University of Balearic Islands, Cra. Valldemossa km 7.5, Palma de Mallorca, E07122, Spain. ${ }^{2}$ ITMO University, 49 Kronverkskiy av., St Petersburg, 197101, Russia. ${ }^{3}$ Key Laboratory for Liquid-Solid Structural Evolution and Processing of Materials, Shandong University, Jingshi Road 17923, Jinan, 250061, China. ${ }^{4}$ Department of Earth Sciences, University of Cambridge, Cambridge, CB2 3EQ, England. ${ }^{5}$ Xi An Jiao Tong University, State Key Laboratory for Mechanical Behaviour of Materials, Xian, 710049, Shaanxi, China. Correspondence and requests for materials should be addressed to S.K. (email: Sergey.Kustov@uib.es)
} 